\title{
Golimumab in unresponsive ulcerative colitis
}

\author{
This article was published in the following Dove Press journal: \\ Biologics:Targets and Therapy \\ 27 May 2014 \\ Number of times this article has been viewed
}

\section{Elisabeth Lippert \\ Martina Müller \\ Claudia Ott \\ University Hospital Regensburg, Department of Internal Medicine I, Regensburg, Germany}

Correspondence: Elisabeth Lippert Department of Internal Medicine I, University of Regensburg,

93042 Regensburg, Germany

Tel +499419447166

Fax +49 491 9447123

Email elisabeth.lippert@klinik.uniregensburg.de

\begin{abstract}
Ulcerative colitis (UC) is a chronic inflammation mainly affecting the colon mucosa. It predominantly occurs in younger patients. Until recently, the main goals in the treatment of UC were to temper the symptoms, such as diarrhea, pain, and weight loss, by using mesalazine and steroids. With newer medications, such as immunomodulators (thiopurines) and the biologics providing blockade of tumor necrosis factor (TNF), the goals of the therapy in UC have changed to long-term remission and mucosal healing. The first available anti-TNF therapy in UC included infusion therapy with infliximab every few weeks. In 2012, subcutaneously administered adalimumab gained approval for the treatment of UC in Germany. In patients with a mild disease, therapy with mesalazine, orally or topically, can be sufficient. In patients with moderate to severe disease, therapy with azathioprine or anti-TNF is often required to reach disease control; however, this is only efficient in about two-thirds of patients. Some patients either show no response or a lost response while on treatment. So, further medical options are warranted in the treatment of UC. With golimumab, a new approach in the treatment of mild to moderate UC recently became available in Germany and is a promising new option in the therapy regimen for patients with UC.
\end{abstract}

Keywords: anti-TNF, biological therapy, inflammatory bowel disease

\section{Background}

Ulcerative colitis (UC) is a chronic inflammatory bowel disease (IBD) affecting mainly the colon mucosa, in contrast to Crohn's disease (CD) in which every part of the gastrointestinal tract can be involved. The onset of the disease mainly occurs in younger patients. The incidence (up to 20 cases per 100,000 persons ${ }^{1}$ ) and prevalence rates are high in western countries such as Europe, North America, and the UK and seem to have stabilized, while the rates of IBD are rising in many developing countries. The disease intensity can vary between mild to severe. The clinical symptoms in UC comprise bloody diarrhea, abdominal pain, weight loss, and malabsorption.

Although there has been huge progress concerning the pathogenesis of the disease within the last years, the main causes of UC still remain unclear. Environmental factors, immunologic factors, and genetic susceptibility seem to partly contribute to the development of chronic inflammation in the gut. . $^{2,3}$

\section{Conventional therapy}

A few years ago, the therapy of moderate UC consisted of mesalazine, administered orally and locally; the use of immunomodulators, such as thiopurines; and, in refractory cases, steroids; surgery was the final option to control the disease. As well, in a steroid-refractory patient, cyclosporines could be helpful. ${ }^{4}$ 
Due to a better understanding of the underlying mechanisms, the approval of antitumor necrosis factor (anti-TNF) medication changed the therapy algorithm in UC. Primarily, infliximab, a chimeric anti-TNF antibody given intravenously, made its way to clinics. ${ }^{5}$ The Active Ulcerative Colitis Trials (ACT) 1 and 2 revealed a rapid response to infliximab with respect to clinical response, mucosal healing and long-term clinical remission. The side effects of infliximab, such as infectious complications or infusion reactions, were reported to be similar in all the study groups (infliximab $5 \mathrm{mg} / \mathrm{kg}$, infliximab $10 \mathrm{mg} / \mathrm{kg}$ or placebo) and to be acceptable and comparable with those of placebo. ${ }^{6,7}$ Colectomy rates were lower in both infliximab-treated groups compared with those in the placebo group, at week $54 .^{8}$

Similar to Crohn's disease, adalimumab, a fully human monoclonal anti-TNF antibody, was also approved for the therapy of moderate to severe UC patients, in Europe in early 2012. The Ulcerative Colitis Long-Term Remission and Maintenance with Adalimumab studies (ULTRA-1 and ULTRA-2) clearly demonstrated the benefit of a therapy with adalimumab with respect to induction of remission as well as its role in maintenance at week 8 and week 52 . The treatment with adalimumab subcutaneous (sc) was generally well tolerated. Mostly injection site reactions were reported, but also, malignancies (one squamous cell carcinoma and one gastric cancer in the adalimumab-treated group) were described. ${ }^{9}$

Current treatment goals in the treatment of UC have changed from symptom control to a modern, more aggressive therapy agenda targeting, again, symptom control but also, mucosal healing, long-term remission, reduction of steroid use, and decreased colectomy rates.

Despite clear progress and change in the therapy of UC, only about two-thirds of all patients respond to a conventional therapy with infliximab or adalimumab. ${ }^{6,9}$ For those patients not responding or losing response while being on therapy, further medical options are strongly needed. Golimumab, a new member of the anti-TNF family, seems to be a promising new medical treatment option in the therapy of ulcerative colitis.

\section{Golimumab}

Golimumab is a human anti-TNF monoclonal antibody binding soluble and transmembrane TNF- $\alpha$ (therefore, the binding of TNF to its receptors, with consequent activation of inflammation, is inhibited). It is administered subcutaneously.

Since 2009, the therapy of golimumab has been approved for the treatment of autoimmune diseases, such as rheumatoid arthritis, psoriatic arthritis, and ankylosing spondylitis, in Europe.

Golimumab has shown efficacy in the treatment of active rheumatoid arthritis when given as treatment in addition to oral methotrexate therapy ${ }^{10,11}$ or as a single treatment regimen. ${ }^{12}$ The symptoms of patients with psoriatic arthritis were significantly improved with the treatment of golimumab over 6 months. $^{13}$

Compared with other anti-TNF agents, side effects in those patients were similar, and golimumab was regarded to be safe in those patients. ${ }^{14}$

\section{Induction therapy}

For patients with UC, an important step forward was taken with the Program of Ulcerative Colitis Research Studies Utilizing an Investigational Treatment (PURSUIT) subcutanous study investigating new therapeutic options. ${ }^{15}$ This was a multicenter, randomized, double-blind, placebo-controlled Phase II trial, conducted between 2007 and 2010. Patients with moderate to severe UC were included, presenting with a Mayo score ranging from 6-12. Patients had not yet received any anti-TNF medication at the time of inclusion. This Phase II trial was aimed to be a dose-finding study. A total of 169 patients were enrolled, in four subgroups: placebo, or golimumab with 100/50 mg (weeks 0 and 2), 200/100 mg, and $400 / 200 \mathrm{mg}$ by sc administration. After 6 weeks of treatment, most patients in the golimumab 400/200 mg sc group had responded or showed a benefit concerning mucosal healing (Figure 1). The authors described an exposure-response relationship in the Mayo score, with best improvement

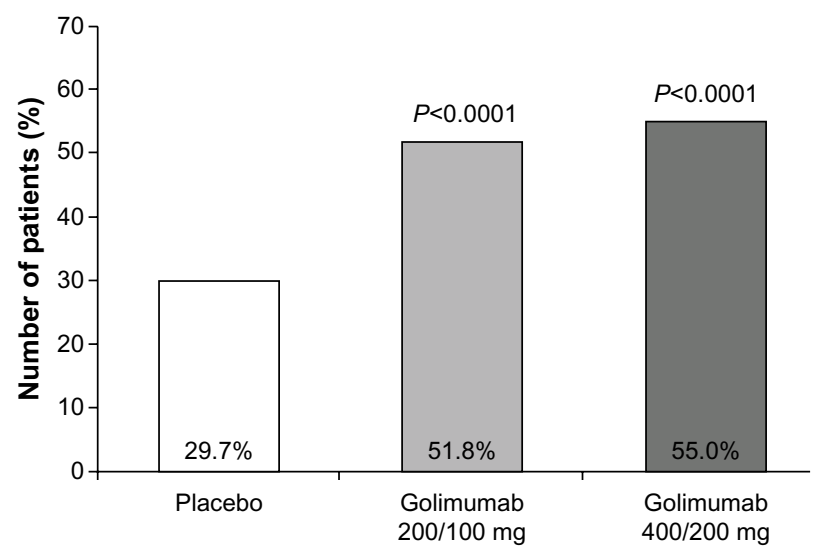

Figure I Golimumab responses in patients with UC to golimumab or placebo at week 6 (clinical response).

Note: Reprinted from Gastroenterology, I46(I), Sandborn W], Feagan BG, Marano C, et al, Subcutaneous golimumab induces clinical response and remission in patients with moderate-to-severe ulcerative colitis, 85-95, Copyright (C) (2014), with permission from Elsevier. ${ }^{15}$

Abbreviation: UC, ulcerative colitis. 
in the patients who received 400/200 $\mathrm{mg}$ of golimumab. Adverse events were rather similar in the placebo- and golimumab-treated groups, being mostly infectious problems or headache. One patient died due to surgical complications, and another patient was reported to have a demyelinating disease. Therefore, the $400 / 200 \mathrm{mg}$ as well as the $200 / 100$ mg application doses were selected to be evaluated in the following Phase III trial.

The aim of the second part of the PURSUIT-SC studybased on the data of the Phase II trial - was to evaluate the safety and efficacy of the final sc golimumab induction regimens. ${ }^{15} \mathrm{~A}$ total of 771 patients were eligible and initially randomized in three groups in the Phase III trial: placebo; golimumab 400/200 mg and golimumab 200/100 mg. The endpoint of this Phase III trial was clinical response at week 6 . The golimumab-treated patients had significantly greater clinical response (51.8\% for golimumab 200/100 $\mathrm{mg}$ and $55.0 \%$ for golimumab $400 / 200 \mathrm{mg}$ ) than did the patients receiving placebo $(29.7 \%)(P<0.0001)$.

\section{Maintenance therapy}

In their Phase III multicenter study, Sandborn et al investigated the effect of golimumab for maintenance in patients with moderate UC, including those patients having completed the induction trials (PURSUIT) successfully. A total of 1,228 patients were included in three groups, depending on their initial response status: placebo, $50 \mathrm{mg}$ golimumab every 4 weeks, and $100 \mathrm{mg}$ golimumab every 4 weeks, for 1 year. ${ }^{15}$ Response rates were calculated via a decrease of Mayo score, at weeks 0,30 , and 54 . The primary endpoint was defined by the clinical response and maintenance at week 54 . The secondary aims were clinical remission as well as mucosal healing (week 30 and 54). Again, the golimumab-treated patients had significantly greater maintenance of clinical response through week 54 compared with placebo $(100$ mg: 50.6\%; $50 \mathrm{mg}$ : 47.1\%; and placebo: $31.4 \%)(P<0.001)$ (Figure 2). Clinical remission, at weeks 30 and 54 was significantly higher in patients receiving $100 \mathrm{mg}(28.6 \%)$ or 50 $\mathrm{mg}(23.5 \%)$ golimumab compared with placebo (15.4\%). However, only remission for the $100 \mathrm{mg}$ golimumab-treated group was statistically significant (Figure 2).

Accordingly, mucosal healing was significantly higher in the golimumab-treated patients (100 mg: $43.5 \%$; $50 \mathrm{mg}$ : $41.8 \%$ ) compared with placebo (26.9\%) (Figure 2).

Concerning the safety profile, infectious problems as well as adverse events were similar for all the treatment groups. Three deaths were reported in patients taking $100 \mathrm{mg}$ golimumab (malnutrition and sepsis; cardiac failure; and disseminated
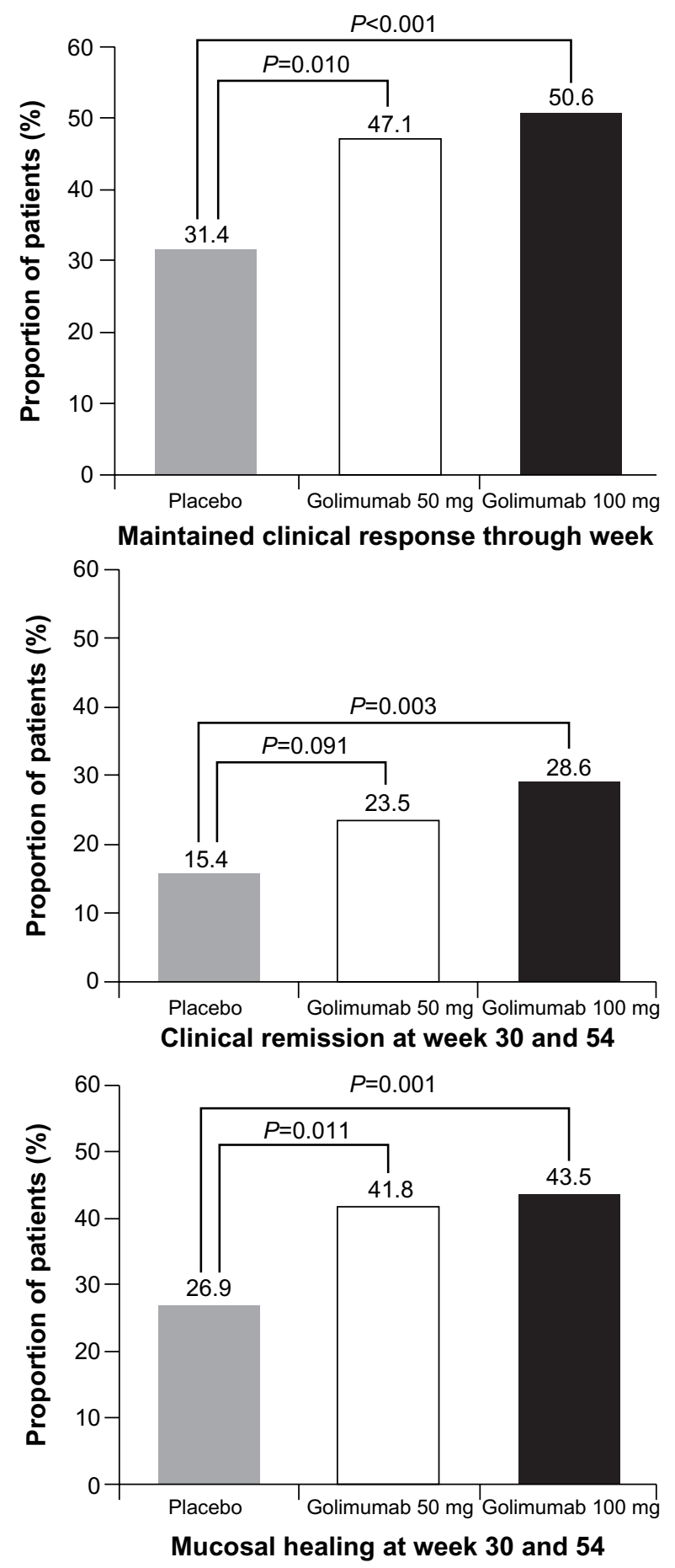

Figure 2 Clinical response, clinical remission, and mucosal healing, with golimumab in the maintenance therapy.

Note: Reprinted from Gastroenterology, I46(I), Sandborn WJ, Feagan BG, Marano C, et al, Subcutaneous golimumab maintains clinical response in patients with moderateto-severe ulcerative colitis, 96-109. el, Copyright (C) (2014), with permission from Elsevier. ${ }^{16}$

tuberculosis) at week 54. Afterwards, six further deaths were documented (infectious problems, cardiac problems, cancer, and accidental nitrous oxide overdose). Overall, the authors concluded that golimumab offers a huge benefit in the maintenance of UC over 54 weeks compared with placebo. ${ }^{16}$ 


\section{Conclusion}

With these data, golimumab seems to be an alternative and new medical option in the therapy of moderate UC. It was effective in early remission as well as in long-term maintenance therapy. The safety profile in patients with UC is acceptable. However, one needs to keep in mind that one patient suffered demyelinating disease, and the occurrence of infectious problems is similar to that with other anti-TNF agents.

In 2011, a case report of three patients showed a negative effect of golimumab in resolving a flare in patients with $\mathrm{CD}$ and extraintestinal manifestations. ${ }^{17}$ So far, the data of golimumab in patients with CD are lacking, and we are waiting for further studies to be published. Additionally, in UC patients, the comparison of which anti-TNF medications works best in first, second, or third place remains unclear. So at this point, doctors need to discuss with patients on an individual basis which of the anti-TNF medication should be started first and which administration format fits best in their period of life. Especially the 4-week administration schedule of golimumab is a clear advantage compared with a 2-week schedule of adalimumab; however, a doctor's appointment for the infliximab infusion might be preferred by patients, especially at younger age.

Thus, a new anti-TNF agent, golimumab, has made its way into clinics to improve and complement the treatment options for patients with UC.

\section{Disclosure}

The authors declare no conflict of interest in this work.

\section{References}

1. Danese S, Fiocchi C. Ulcerative colitis. N Engl J Med. 2011;365(18): 1713-1725.

2. Sartor RB. Innate immunity in the pathogenesis and therapy of IBD. J Gastroenterol. 2003;38 Suppl 15:S43-S47.

3. Rogler G. Update in inflammatory bowel disease pathogenesis. Curr Opin Gastroenterol. 2004;20(4):311-317.
4. Lissner D, Siegmund B. Ulcerative colitis: current and future treatment strategies. Dig Dis. 2013;31(1):91-94.

5. Rutgeerts P, Sandborn WJ, Feagan BG, et al. Infliximab for induction and maintenance therapy for ulcerative colitis. $N$ Engl J Med. 2005; 353(23):2462-2476.

6. Reinisch W, Sandborn WJ, Rutgeerts P, et al. Long-term infliximab maintenance therapy for ulcerative colitis: the ACT- 1 and -2 extension studies. Inflamm Bowel Dis. 2012;18(2):201-211.

7. Colombel JF, Rutgeerts P, Reinisch W, et al. Early mucosal healing with infliximab is associated with improved long-term clinical outcomes in ulcerative colitis. Gastroenterology. 2011;141(4):1194-1201.

8. Sandborn WJ, Rutgeerts P, Feagan BG, et al. Colectomy rate comparison after treatment of ulcerative colitis with placebo or infliximab. Gastroenterology. 2009;137(4):1250-1260; quiz 1520.

9. Sandborn WJ, van Assche G, Reinisch W, et al. Adalimumab induces and maintains clinical remission in patients with moderate-to-severe ulcerative colitis. Gastroenterology. 2012;142(2):257-265. e1.

10. Keystone EC, Genovese MC, Klareskog L, et al; GO-FORWARD Study. Golimumab, a human antibody to tumour necrosis factor \{alpha\} given by monthly subcutaneous injections, in active rheumatoid arthritis despite methotrexate therapy: the GO-FORWARD Study. Ann Rheum Dis. 2009;68(6):789-796.

11. Smolen JS, Kay J, Matteson EL, et al. Insights into the efficacy of golimumab plus methotrexate in patients with active rheumatoid arthritis who discontinued prior anti-tumour necrosis factor therapy: post-hoc analyses from the GO-AFTER study. Ann Rheum Dis. 2013.

12. Smolen JS, Kay J, Doyle MK, et al; GO-AFTER study investigators. Golimumab in patients with active rheumatoid arthritis after treatment with tumour necrosis factor alpha inhibitors (GO-AFTER study): a multicentre, randomised, double-blind, placebo-controlled, phase III trial. Lancet. 2009;374(9685):210-221.

13. Kavanaugh A, McInnes I, Mease P, et al. Golimumab, a new human tumor necrosis factor alpha antibody, administered every four weeks as a subcutaneous injection in psoriatic arthritis: Twenty-four-week efficacy and safety results of a randomized, placebo-controlled study. Arthritis Rheum. 2009;60(4):976-986.

14. Yang H, Kavanaugh A. Adverse effects of golimumab in the treatment of rheumatologic diseases. Expert Opin Drug Saf. 2014;13(1):103-112.

15. Sandborn WJ, Feagan BG, Marano C, et al; PURSUIT-SC Study Group. Subcutaneous golimumab induces clinical response and remission in patients with moderate-to-severe ulcerative colitis. Gastroenterology. 2014;146(1):85-95.

16. Sandborn WJ, Feagan BG, Marano C, et al; PURSUIT-Maintenance Study Group. Subcutaneous golimumab maintains clinical response in patients with moderate-to-severe ulcerative colitis. Gastroenterology. 2014;146(1):96-109. e1.

17. Fiehn C, Vay S. Induction of inflammatory bowel disease flares by golimumab: report of three patients with enteropathic spondylarthritis or ankylosing spondylitis and comorbid colitis. Arthritis Rheum. 2011;63(11):3640-3641.
Biologics: Targets \& Therapy

\section{Publish your work in this journal}

Biologics: Targets \& Therapy is an international, peer-reviewed journal focusing on the patho-physiological rationale for and clinical application of Biologic agents in the management of autoimmune diseases, cancers or other pathologies where a molecular target can be identified. This journal is indexed on PubMed Central, CAS, EMBase, Scopus
Dovepress

and the Elsevier Bibliographic databases. The manuscript management system is completely online and includes a very quick and fair peerreview system, which is all easy to use. Visit http://www.dovepress. com/testimonials.php to read real quotes from published authors. 